\title{
Changes of strength and maximum power of lower extremities in adolescent handball players during a two-year training cycle
}

\author{
by \\ Michat Górski, Michał Starczewski², Anna Pastuszak1, Joanna Mazur-Różycka², \\ Jan Gajewski ${ }^{4}$ Krzysztof Buśko ${ }^{5}$
}

The aim of the study was to investigate changes of strength and power of the lower extremities in adolescent handball players during a two-year training cycle. Thirty-one male handball players (age $16.0 \pm 0.2$ years, body mass $81.4 \pm 9.7 \mathrm{~kg}$, body height $188.2 \pm 6.4 \mathrm{~cm}$ ) took part in this study. All tests were conducted three times at the beginning of a one-year training programme. The maximum joint torque (JT) of flexors and extensors of the elbow, shoulder, hip, knee and trunk was measured under static conditions. Power of lower extremities was assessed with a repeated sprint ability (RSA) test on a cycloergometer and jump tests: akimbo counter-movement jump (ACMJ), counter-movement jump (CMJ) and spike jump tests on a force plate. Peak power (PP) increased from $914.8 \pm 93.9$ to $970.0 \pm 89.2$ and $1037.8 \pm 114.4 W(p<0.05)$ following the RSA test results. Maximum power increased significantly $(p<0.05)$ in ACMJ (1951.9 \pm 359.7 to $2141.9 \pm 378.5$ and $2268.5 \pm 395.9 W)$ and CMJ tests $(2646.3 \pm 415.6$ to $2831.2 \pm 510.8$ and $3064.6 \pm 444.5 \mathrm{~W})$. Although significant differences in JT $(p<0.05)$ were observed during the two year period, their values related to body mass for the lower right extremity, sum of the trunk and sum of all muscle groups increased significantly between the first and the second measurement (from $13.7 \pm 1.8$ to $14.58 \pm 1.99 \mathrm{~N} \cdot \mathrm{m} \cdot \mathrm{kg}^{-1}$, from $9.3 \pm 1.5$ to $10.39 \pm 2.16 \mathrm{~N} \cdot \mathrm{m} \cdot \mathrm{kg}^{-1}$, from $43.4 \pm 5.2$ to $46.31 \pm 6.83 \mathrm{~N} \cdot \mathrm{m} \cdot \mathrm{kg}^{-1}$, respectively). The main finding of the study is that PP in the RSA test and maximal power in the ACMJ and CMJ increase in relation to training experience and age in the group of youth handball players.

Key words: RSA test, akimbo counter-movement jump, countermovement jump, spike jump, joint torque.

\section{Introduction}

Handball requires good technical, tactical and motor preparation. During a handball match players have to perform a number of speedstrength tasks such as sprints, sudden changes in movement direction, jumps, blocks, pushes, and throws (Gorostiaga et al., 1999, 2005, 2006; Thorlund et al., 2008). Therefore, besides aerobic and anaerobic capacities, athletes should possess a high level of muscle strength, speed and endurance abilities (Marques and GonzalezBadillo, 2006) as well as skills to throw the ball with a high speed (Marques et al., 2007) .

Anaerobic capabilities of handball players are often assessed in repeated sprint capabilities based on running tests and/or cycloergometer tests (Chittibabu, 2014; Gharbi et al., 2015; Hermassi et al., 2015; Nikolaidis and Ingebrigtsen, 2013). It is suggested that there is a relationship between the results of the RSA test and sport results in team games, including handball (Gharbi et al., 2015).

Isotonic, isokinetic and isometric testing is

\footnotetext{
1 - Institute of Sport - National Research Institute, Dept. of Biomechanics, Warszawa, Poland.

2 - Institute of Sport - National Research Institute, Dept. of Physiology, Warszawa, Poland.

3 - Central Institute For Labour Protection - National Research Institute (CIOP- PIB), Dept. of Ergonomics, Warszawa, Poland.

4 - Józef Piłsudski University of Physical Education, Dept. of Statistics and Information Technology, Warszawa, Poland.

5 - Dept. of Anatomy and Biomechanics, Kazimierz Wielki University, Bydgoszcz, Poland .
} 
used to measure maximum force (Boguszewska et al., 2010; Szulc et al., 2017). The upper extremity strength of handball players is most often assessed using a one-repetition maximum benchpress, since this action seems most specific to the overhand throwing technique (Gorostiaga et al., 2006; Granados et al., 2008). Significant changes in this variable in the 45 -week season in elite players were between 1 and 4\% (Gorostiaga et al., 2006). As observed by Chelly et al. (2010), the upper extremity strength correlated with throwing velocity. A high speed of the ball means a decreased time for defenders and a goalkeeper for parrying the throw (Gorostiaga et al., 2005).

The speed of the thrown ball may also be affected by explosive strength of the lower limbs. The ball speed correlates with height of the jump in the counter-movement jump (Marques and Gonzalez-Badillo, 2006). Gorostiaga et al. (2006) stated that the height of the jump did not change significantly in elite handball players during the whole season. Jumping ability did not differentiate elite from amateur players neither with regard to adolescents (Bencke et al., 2002), nor adults (Gorostiaga et al., 2005).

Control tests of motor abilities are usually disposable measurements, in which the results of young and old, elite and non-elite are compared (Granados et al., 2007; Matthys et al., 2013). Continuous monitoring of athletes' motor abilities seems to be crucial for controlling optimum training programmes aiming to improve sport results. Longitudinal studies help to determine the predictive utility of the implied test battery and consequently improve the understanding of the factors that contribute to expert performance (Williams and Reilly, 2000). We hypothesized that the increase in strength in the two-year training cycle would be accompanied by improved jumping and power. Therefore, the aim of the study was to investigate changes of strength and power of the lower extremities in adolescent handball players during a two-year training cycle.

\section{Methods}

\section{Participants}

The study participants included 31 male handball players (training experience $5.7 \pm 1.6$ years). The handball players were students from a Private Athletic High School of the Polish Handball Federation. None of them reported any injury of the lower limbs for six months prior to the study. Characteristics of the athletes are presented in Table 1.

This study was approved by the Ethics Committee at the Institute of Sport, National Research Institute in Warsaw, Poland (KEBN-17$32-\mathrm{KB})$ and conducted according to the Declaration of Helsinki. All participants (or their legal guardians if the athlete was under 18 years of age) gave their written consent to participate in the study and were informed about the purpose and test procedures. Furthermore they were aware of the possibility to withdraw from the study at any time for any reason.

\section{Procedures}

All tests were conducted at the beginning of a one-year training programme. The research was conducted at the Departments of Biomechanics and Physiology after a standard warm-up in the following order of measurements: joint torque, jump tests and the RSA test.

\section{Muscle strength (maximal joint torque)}

The maximal joint torque (JT) of the flexors and extensors of the elbow, shoulder, hip, knee and trunk was measured under static conditions using a special torque meter (Institute of Sport, Poland; type SMS1 (upper extremities) and SMS2 (lower extremities and trunk)). During the measurements of elbow flexors and extensors, the participant was in a sitting position, with his arm and forearm positioned at a $90^{\circ}$ angle and placed on the armrest, and with the trunk stabilized. The joint torque of the shoulder flexors and extensors was also measured in a sitting position. The flexion angle was set at $70^{\circ}$ and the extension angle was $50^{\circ}$. The trunk was stabilized with the chest pressed against the backrest. The measurements of knee flexors and extensors were carried out in a sitting position. The hip and knee joints were bent at $90^{\circ}$. The participants were stabilized at the level of the anterior and superior iliac spines as well as thighs, with the upper extremities resting on the chest. The subjects were lying face down during the measurements of the hip extensors, and face up during the measurements of the hip flexors. The hip joint angle remained at $90^{\circ}$ during both measurements. The maximal extension of the elbow, knee and hip joints was accepted as $0^{\circ}$. For the shoulder joint, the position of the arm along the side was taken as $0^{\circ}$. The axis of rotation during joint torque 
measurements corresponded to the axis of rotation of the torque meter. Joint torques of the right and left limb were measured separately, always in the order flexion-extension. The subjects were instructed to develop maximal possible force.

The total error in the measurement of the maximal torque did not exceed $4 \%$. The maximal error of repeatability, expressed by the coefficient of variation, was $4.2 \%$, while for the individual muscle groups it was $4.9 \%$ for hip flexors, $6.3 \%$ for shoulder extensors, and $1.8 \%$ and $2.1 \%$ for knee and hip extensors, respectively (Orysiak et al., 2015).

\section{Repeated sprint ability (RSA) test}

Power of lower extremities was measured assessing repeated sprint ability (RSA). The $5 \times 6$ repeated sprint cycle ergometry test on a Monark $874 \mathrm{E}$ with a friction load of $7.5 \%$ of body mass was conducted to evaluate RSA. Following a 5min warm up (about $70 \mathrm{~W}$ ), each athlete was allowed a 5-min recovery before performing the test. The $5 \times 6$ sprint cycle test comprised five 6-s maximal sprints commencing every 30 s. All sprints were performed from a stopped position and passive recovery was utilized between sprints. Five seconds before starting the next sprint, the athlete adopted a ready position and waited for the start.

Absolute (total $\mathrm{kJ}$ and $\mathrm{W}$ ) and relative $\left(\mathrm{J} \cdot \mathrm{kg}^{-1}\right.$ and $\left.\mathrm{W} \cdot \mathrm{kg}^{-1}\right)$ work and power scores were calculated along with their respective decrement scores (\% of decrement over repeated efforts). The equations for the decrement score calculation were as follows:

Decrement of work:

$\mathrm{DW}=100-\left(\mathrm{W} \cdot\left(\mathrm{W}^{\prime} \cdot 5\right)^{-1} \cdot 100\right)$,

where:

DW $=$ decrement of work,

$\mathrm{W}=$ total work,

$\mathrm{W}^{\prime}=$ highest $6 \mathrm{~s}$ work;

Decrement of power:

$\mathrm{DP}=100-\left(\mathrm{P}_{\min } \cdot \mathrm{P}_{\max }{ }^{-1} \cdot 100\right)$,

where:

$\mathrm{DP}=$ decrement of power,

$P_{\min }=$ lowest $6 \mathrm{~s}$ power,

$P_{\max }=$ highest $6 \mathrm{~s}$ power.

The method used to determine total work and the decrement (\%) in power and work had been described previously (Bishop et al., 2004). The cycling protocol provides both a valid and reliable test of RSA (Bishop et al., 2001). The coefficient of variation (CV) for RSA (total work; $\mathrm{kJ}$ ) was $3.7 \%$, based on a study of Edge et al. (2005) in recreationally active female students with a five-week separation period (similar to the current study).

\section{Power output and height of jump}

Power of lower extremities and the height of the rise of the body mass centre (COM) during vertical jumps were measured using a force plate ("JBA" Zb. Staniak, Poland). The MVJ v. 3.4 software package ("JBA" Zb. Staniak, Poland) was used for measurements. Absolute peak power $\left(P_{\max }(\mathrm{W})\right)$, relative peak power $\left(\mathrm{P}_{\max \cdot \operatorname{mass}}{ }^{-1}\left(\mathrm{~W} \cdot \mathrm{kg}^{-1}\right)\right)$ and maximum height of rise of the body's COM $(\mathrm{h}(\mathrm{m}))$ were calculated from the recorded ground reaction force of the force plate (Gajewski et al., 2018). Each participant performed 9 vertical jumps on the force plate: three jumps of each kind. The characteristics of each jump test were as follows:

ACMJ: akimbo counter-movement jump, a vertical jump from an upright standing position with hands on the hips and counter-movement of the COM before the take-off;

CMJ: counter-movement jump, a vertical jump from a standing erect position, preceded by an arm-swing and counter-movement of the body COM before the take-off;

SPJ: spike jump, a vertical jump which is performed with a 3-4 step run-up before the takeoff. The participant's task was to take off and land on the force plate.

The participants were asked to jump as high as possible in each trial. There were $5 \mathrm{~s}$ rest intervals between each ACMJ and CMJ and a 1 min rest interval between the SPJs. There was also a 1 min rest interval between each series of jumps. The jump with the highest elevation of the body's $\mathrm{COM}$ was chosen for further analysis.

The total error in the measurement of the maximal power output and jump height did not exceed $3.3 \%$ and $4.5 \%$, respectively. The maximal error of repeatability, expressed by the coefficient of variation, for maximal power output was 3.4\% and 3.0\% for jump height (Orysiak et al., 2015).

\section{Statistical analysis}

Prior to the statistical analysis, tests for 
normality (Kolmogorov-Smirnov and ShapiroWilk) were carried out on all variables. The analysis of variance (ANOVA) for repeated measures was used to compare the study results. The significance of differences between means was evaluated post hoc with the Scheffé test. Relationships between all variables were assessed by calculating the Pearson's linear correlation coefficient. The level of significance was set at $p<$ 0.05. All calculations were performed with STATISTICA software (v. 12.0, StatSoft, USA).

\section{Results}

Peak power (PP) significantly increased ( $p$ $<0.05$ ) between measurements I and II, I and III as well as between measurements II and III (regarding relative average power, the increases were significant between measurements I and III). Also absolute work (AW) increased significantly between measurements I and II, I and III as well as between measurements II and III in the RSA test (Table 2).

Maximum power and height of the jump increased significantly $(p<0.05)$ between measurements I and II, as well as I and III in the ACMJ and CMJ. Significant increases were also observed when comparing measurements I and III in the SPJ (Table 3). Changes in relative maximum power in the SPJ were non-significant.

Although significant differences in the JT $(p<0.05)$ were observed during the two year period, their values related to body mass for the lower right extremity, sum of the trunk and sum of all muscle groups increased significantly only between the first and the second measurement (Tables 4 and 5). In other cases, the changes were non-significant.

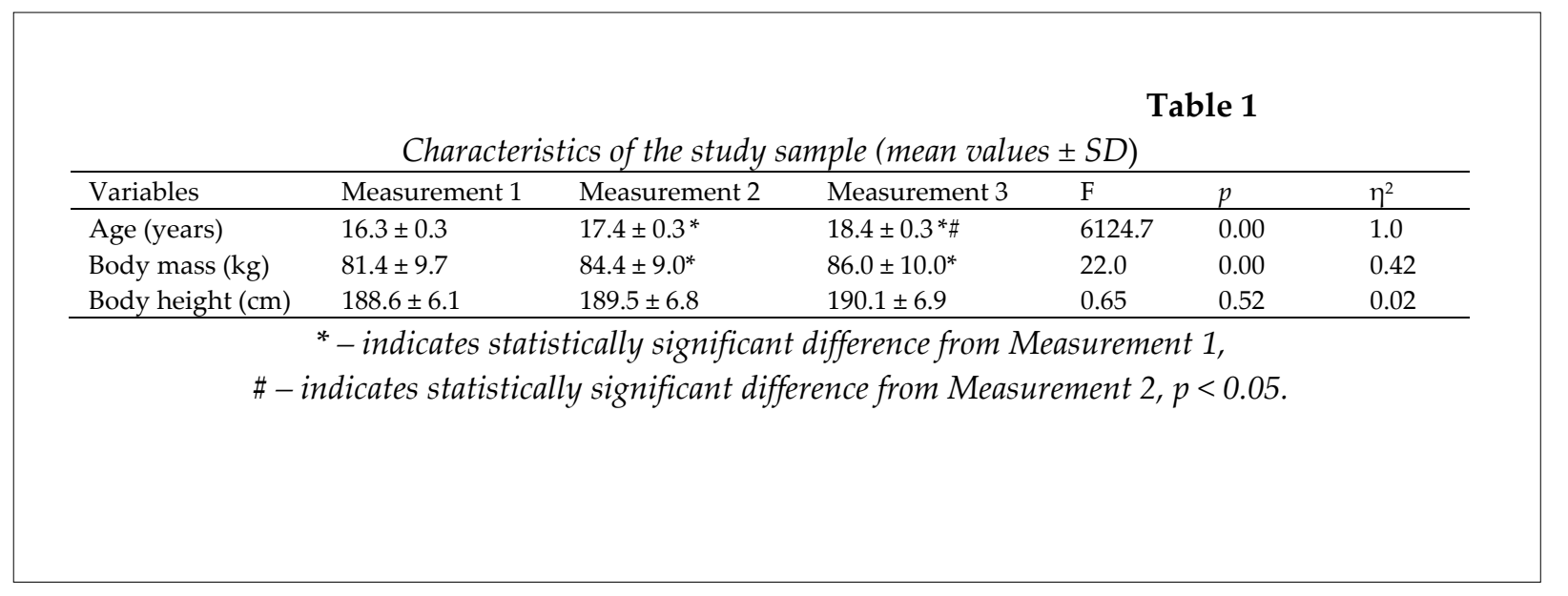

Table 2

Changes in mean values $( \pm S D$ ) of power and work developed in the RSA test by handball players

\begin{tabular}{|c|c|c|c|c|c|c|}
\hline Variables & Measurement 1 & Measurement 2 & Measurement 3 & $\mathrm{~F}$ & $\mathrm{P}$ & $\eta^{2}$ \\
\hline Peak power $(\mathrm{W})$ & $914.8 \pm 93.9$ & $970.0 \pm 89.2^{*}$ & $1037.8 \pm 114.4^{* \#}$ & 70.95 & 0.00 & 0.70 \\
\hline $\begin{array}{l}\text { Relative peak power } \\
\left(\mathrm{W} \cdot \mathrm{kg}^{-1}\right)\end{array}$ & $11.3 \pm 0.6$ & $11.5 \pm 0.7^{*}$ & $11.9 \pm 0.8^{*} \#$ & 22.90 & 0.00 & 0.43 \\
\hline $\begin{array}{l}\text { Relative average } \\
\text { power }\left(\mathrm{W} \cdot \mathrm{kg}^{-1}\right)\end{array}$ & $10.8 \pm 0.5$ & $11.0 \pm 0.6$ & $11.1 \pm 0.6^{*}$ & 10.31 & 0.00 & 0.26 \\
\hline $\mathrm{DP}(\%)$ & $8.9 \pm 4.0$ & $10.3 \pm 3.2$ & $12.9 \pm 4.4^{* \#}$ & 10.46 & 0.00 & 0.26 \\
\hline Absolute work (kJ) & $20.5 \pm 2.4$ & $22.0 \pm 2.0^{*}$ & $23.9 \pm 3.1^{* \#}$ & 52.23 & 0.00 & 0.64 \\
\hline Relative work (J·kg-1 $)$ & $252.7 \pm 16.0$ & $260.4 \pm 13.5$ & $274.1 \pm 20.9^{* \#}$ & 20.07 & 0.00 & 0.40 \\
\hline DW (\%) & $4.2 \pm 1.5$ & $4.5 \pm 2.2$ & $6.3 \pm 3.2^{* \#}$ & 8.86 & 0.00 & 0.23 \\
\hline
\end{tabular}

Legend: $D P$-decrement of power, DW-decrement of work;

* - indicates statistically significant difference from Measurement 1, $\#$ - indicates statistically significant difference from Measurement 2, $p<0.05$. 
Table 3

Height of the body mass centre during vertical jumps ( $h)$, maximal power $\left(P_{\max }\right)$, relative maximal power $\left(P_{\max } B M^{-1}\right)$ during the $A C M J, C M J$ and SPJ jumps on the force plate (means $\pm S D$ )

\begin{tabular}{|c|c|c|c|c|c|c|}
\hline Variables & Measurement 1 & Measurement 2 & Measurement 3 & F & $p$ & $\eta^{2}$ \\
\hline $\mathrm{h}_{\text {ACMJ }}(\mathrm{m})$ & $0.375 \pm 0.039$ & $0.388 \pm 0.042 *$ & $0.394 \pm 0.042^{*}$ & 7.81 & 0.00 & 0.21 \\
\hline hсмJ $(\mathrm{m})$ & $0.441 \pm 0.041$ & $0.455 \pm 0.044^{*}$ & $0.462 \pm 0.047^{*}$ & 7.57 & 0.00 & 0.20 \\
\hline hspJ (m) & $0.539 \pm 0.069$ & $0.555 \pm 0.066$ & $0.565 \pm 0.062^{*}$ & 5.14 & 0.09 & 0.15 \\
\hline$P_{\max A C M J}(\mathrm{~W})$ & $1951.9 \pm 359.7$ & $2141.9 \pm 378.5^{*}$ & $2268.5 \pm 395.9^{*}$ & 13.81 & 0.00 & 0.32 \\
\hline$P_{\max C M J}(\mathrm{~W})$ & $2646.3 \pm 415.6$ & $2831.2 \pm 510.8^{*}$ & $3064.6 \pm 444.5^{* \#}$ & 17.70 & 0.00 & 0.37 \\
\hline$P_{\operatorname{maxSPJ}}(\mathrm{W})$ & $3899.5 \pm 759.3$ & $4111.7 \pm 935.1$ & $4241.7 \pm 855.6^{*}$ & 3.95 & 0.03 & 0.12 \\
\hline $\begin{array}{l}P_{\max A C M J} \cdot \mathrm{BM}^{-1} \\
\left(\mathrm{~W} \cdot \mathrm{kg}^{-1}\right)\end{array}$ & $24.18 \pm 4.78$ & $25.56 \pm 4.72$ & $26.56 \pm 4.60^{*}$ & 5.19 & 0.01 & 0.15 \\
\hline $\begin{array}{l}\mathrm{P}_{\max C M J} \cdot \mathrm{BM}^{-1} \\
\left(\mathrm{~W} \cdot \mathrm{kg}^{-1}\right)\end{array}$ & $32.68 \pm 5.06$ & $33.66 \pm 5.58$ & $36.02 \pm 6.11 * \#$ & 7.43 & 0.00 & 0.20 \\
\hline $\begin{array}{ll}\mathrm{P}_{\max S P J} & \cdot \mathrm{BM}^{-1} \\
\left(\mathrm{~W} \cdot \mathrm{kg}^{-1}\right) & \end{array}$ & $48.25 \pm 9.53$ & $48.99 \pm 11.09$ & $49.63 \pm 10.04$ & 0.46 & 0.63 & 0.02 \\
\hline
\end{tabular}

Legend: ACMJ - akimbo countermovement jump; CMJ - countermovement jump; SPJ - spike jump;

* - indicates statistically significant difference from Measurement 1 ,

$\#-$ indicates statistically significant difference from Measurement 2, $p<0.05$.

\begin{tabular}{|c|c|c|c|c|c|c|}
\hline \multicolumn{7}{|c|}{$\begin{array}{c}\text { Changes in mean values }( \pm S D) \text { of the maximal joint torque }(N \cdot m) \text { of the sum } \\
\text { of the joint torque of the upper (SUE) and lower (SLE) extremities, the trunk }(S T) \text {, } \\
\text { and ten muscle groups (TOTAL), upper right (SUER) and lower right (SLER) extremities, } \\
\text { upper left (SUEL) and lower left (SLEL) extremities }\end{array}$} \\
\hline Variables & Measurement 1 & Measurement 2 & Measurement 3 & $\mathrm{~F}$ & $p$ & $\eta^{2}$ \\
\hline SUER $(\mathrm{N} \cdot \mathrm{m})$ & $272.2 \pm 36$ & $294.0 \pm 43.9^{*}$ & $300.7 \pm 42.2^{*}$ & 7.18 & 0.02 & 0.19 \\
\hline SLER $(\mathrm{N} \cdot \mathrm{m})$ & $1110.5 \pm 162.7$ & $1226.2 \pm 159.4^{*}$ & $1215.3 \pm 160.3^{*}$ & 10.52 & 0.00 & 0.26 \\
\hline SUEL $(\mathrm{N} \cdot \mathrm{m})$ & $270.8 \pm 35.7$ & $288.2 \pm 34.4^{*}$ & $301.1 \pm 40.5^{*}$ & 9.75 & 0.00 & 0.25 \\
\hline SLEL $(\mathrm{N} \cdot \mathrm{m})$ & $1110.3 \pm 182.1$ & $1209.8 \pm 166.0^{*}$ & $1221.2 \pm 184.1^{*}$ & 7.58 & 0.00 & 0.20 \\
\hline SUE $(N \cdot m)$ & $543.0 \pm 68.0$ & $582.1 \pm 75.4^{*}$ & $601.8 \pm 80.2^{*}$ & 9.15 & 0.00 & 0.23 \\
\hline $\operatorname{SLE}(\mathrm{N} \cdot \mathrm{m})$ & $2220.8 \pm 337.2$ & $2436.1 \pm 316.9^{*}$ & $2436.5 \pm 334.0^{*}$ & 9.53 & 0.00 & 0.24 \\
\hline $\mathrm{ST}(\mathrm{N} \cdot \mathrm{m})$ & $755.2 \pm 135.3$ & $872.8 \pm 168.1^{*}$ & $939.4 \pm 158.0 *$ & 18.39 & 0.00 & 0.38 \\
\hline TOTAL $(\mathrm{N} \cdot \mathrm{m})$ & $3519.0 \pm 495.9$ & $3891.0 \pm 513.3^{*}$ & $3977.7 \pm 509.4^{*}$ & 14.73 & 0.00 & 0.33 \\
\hline
\end{tabular}

\begin{tabular}{|c|c|c|c|c|c|c|}
\hline \multicolumn{7}{|c|}{$\begin{array}{c}\text { Table } 5 \\
\text { Changes in mean values }( \pm S D) \text { of the relative joint torque }\left(N \cdot m \cdot \mathrm{kg}^{-1}\right) \text { of the sum } \\
\text { of the joint torques of the upper (SUE) and lower (SLE) extremities, the trunk }(S T) \text {, } \\
\text { and ten muscle groups (TOTAL), upper right (SUER) and lower right (SLER) extremities, } \\
\text { upper left (SUEL) and lower left (SLEL) extremities }\end{array}$} \\
\hline Variables & Measurement 1 & Measurement 2 & Measurement 3 & $\mathrm{~F}$ & $p$ & $\eta^{2}$ \\
\hline SUER $\left(\mathrm{N} \cdot \mathrm{m} \cdot \mathrm{kg}^{-1}\right)$ & $3.37 \pm 0.43$ & $3.50 \pm 0.60$ & $3.46 \pm 0.54$ & 1.01 & 0.37 & 0.03 \\
\hline $\operatorname{SLER}\left(\mathrm{N} \cdot \mathrm{m} \cdot \mathrm{kg}^{-1}\right)$ & $13.69 \pm 1.75$ & $14.58 \pm 1.99^{*}$ & $13.95 \pm 1.83$ & 3.62 & 0.03 & 0.11 \\
\hline $\operatorname{SUEL}\left(\mathrm{N} \cdot \mathrm{m} \cdot \mathrm{kg}^{-1}\right)$ & $3.35 \pm 0.45$ & $3.44 \pm 0.52$ & $3.47 \pm 0.54$ & 1.10 & 0.35 & 0.04 \\
\hline SLEL $\left(\mathrm{N} \cdot \mathrm{m} \cdot \mathrm{kg}^{-1}\right)$ & $13.68 \pm 1.91$ & $14.40 \pm 2.21$ & $14.03 \pm 2.17$ & 1.91 & 0.16 & 0.06 \\
\hline $\operatorname{SUE}\left(\mathrm{N} \cdot \mathrm{m} \cdot \mathrm{kg}^{-1}\right)$ & $6.72 \pm 0.83$ & $6.94 \pm 1.09$ & $6.93 \pm 1.06$ & 1.06 & 0.35 & 0.03 \\
\hline $\mathrm{SLE}\left(\mathrm{N} \cdot \mathrm{m} \cdot \mathrm{kg}^{-1}\right)$ & $27.37 \pm 3.55$ & $28.99 \pm 4.11$ & $27.99 \pm 3.90$ & 2.82 & 0.07 & 0.07 \\
\hline $\mathrm{ST}\left(\mathrm{N} \cdot \mathrm{m} \cdot \mathrm{kg}^{-1}\right)$ & $9.31 \pm 1.46$ & $10.39 \pm 2.16^{*}$ & $10.73 \pm 1.43^{*}$ & 7.82 & 0.00 & 0.21 \\
\hline TOTAL $\left(\mathrm{N} \cdot \mathrm{m} \cdot \mathrm{kg}^{-1}\right)$ & $43.39 \pm 5.16$ & $46.31 \pm 6.83^{*}$ & $45.65 \pm 5.60$ & 3.81 & 0.03 & 0.11 \\
\hline
\end{tabular}




\section{Discussion}

Longitudinal studies collecting results over years in handball players have been rarely published. Handball is a contact sport, where jumping, hitting, blocking and pushing are common. Strength is a necessity to perform at the highest level in team handball (Ziv and Lidor, 2009). Hence, the aim of the present study was to investigate changes of strength and power of lower extremities in adolescent handball players during a two-year training cycle.

The main finding of the present study was that the jumping ability, maximum power (jumping and RSA test) and maximum strength increased significantly within a two-year training cycle. However, maximum strength related to body mass did not change significantly.

During a handball match players perform series of anaerobic efforts, including jumps and throws. Velocity of the thrown ball correlates with the height of the jump (Marques and GonzalezBadillo, 2006). The height of a jump is usually processed based on either ground reaction forces registered on a force plate (Thorlund et al., 2008; Vicente-Rodriguez et al., 2004) or flight time measured on a contact mat (Gorostiaga et al., 1999, 2005, 2006; Marques and Gonzalez-Badillo, 2006; Matthys et al., 2013). Gorostiaga et al. (1999) and Thorlund et al. (2008) reported that the height of a jump of the handball players tested was $32.0 \pm$ $5.0 \mathrm{~cm}$ and $39.23 \pm 2.08 \mathrm{~cm}$ in the CMJ and ACMJ, respectively. There are different opinions among authors concerning the influence of heavy resistance training on jumping ability. Marques and Gonzalez-Badillo (2006) reported a significant increase in jumping height (CMJ) after 6 and 12 weeks of heavy resistance training. The height of a jump on a contact platform in 16 elite players was $36.82 \pm 4.80 \mathrm{~cm}, 40.55 \pm 5.09 \mathrm{~cm}$ and $41.62 \pm 5.60$ $\mathrm{cm}$ before the season and after 6 and 12 weeks of training, respectively. The age of the athletes taking part in the measurements was $23.1 \pm 4.7$ years. The height of the ACMJ (without an arm swing) in 10 elite handball players of similar age (22.8 \pm 1.5 years) was investigated by Thorlund et al. (2008). Although the force plate was used in that study instead of the contact mat, the results of the measurements were similar: $39.23 \pm 2.08 \mathrm{~cm}$. The reported increases in height of the jump following resistance training were contradictory to the results of Gorostiaga et al. (1999). Those authors found that the height of the jump did not change significantly after 6 weeks of resistance training. The height of the CMJ was $34.2 \pm 3.1 \mathrm{~cm}$ and $35.2 \pm 3.6 \mathrm{~cm}$ before and after the training cycle, respectively; however, it should be noted that it was measured in younger players whose age ranged from 14 to 16 years. This may explain the lower height values achieved by those athletes. Matthys et al. (2013) reported change of height of the CMJ from $42.5 \pm 1.3$ to $43.4 \pm 4.2 \mathrm{~cm}$ following over a three-year period (elite U17 and U18 handball players; body height $178.0 \pm 4.7 \mathrm{~cm}$ and $180.5 \pm 5.1 \mathrm{~cm}$, respectively). Elite players performed on average $8.2 \%$ better on the counter movement jump test. The height of the ACMJ registered in our study was similar to the results published by other authors, yet our players performed significantly better in the CMJ. Changes of the jump height and power observed in our study for the CMJ, ACMJ and SPJ were significant within the two-year training cycle. It is highly probable that the changes we observed may be related to the ongoing physical development of the subjects tested who were examined between the ages of 16-18 years. Following the three measurement points, our handball players had a higher body height (188.6 $\pm 6.1 \mathrm{~cm}, 189.5 \pm 6.8 \mathrm{~cm}$ and $190.1 \pm 6.9 \mathrm{~cm})$. In addition, these changes may also be the result of selection.

Strength is assessed with laboratory and/or field tests. Strength of the lower extremities is usually evaluated by the half squat test (Gorostiaga et al., 2005; Marques and Gonzalez-Badillo, 2006), while the bench-press is used to measure the upper extremity strength of handball players (Chelly et al., 2010; Hermassi et al., 2010; Marques and Gonzalez-Badillo, 2006; Marques et al., 2007). Since van den Tillaar and Ettema (2004) found that the velocity of the thrown ball correlated significantly with the upper extremity strength measured under static conditions, we also measured strength as joint torque in static conditions in our study.

In the study by Thorlund et al. (2008) the maximum torque related to body mass developed by knee flexors and extensors in isometric contraction was $1.77 \pm 0.52$ and $3.90 \pm 0.63 \mathrm{~N} \cdot \mathrm{m} \cdot \mathrm{kg}$ 1, respectively, while Gorostiaga et al. (1999) reported the following values of absolute torques: $111.0 \pm 25.4$ and $225.8 \pm 39.6 \mathrm{~N} \cdot \mathrm{m}$ for 
flexors and extensors, respectively. In our study handball players achieved superior results for knee flexion and extension: $168.5 \pm 27.3 \mathrm{~N} \cdot \mathrm{m}(1.93$ $\left.\pm 0.26 \mathrm{~N} \cdot \mathrm{m} \cdot \mathrm{kg}^{-1}\right)$ and $323.0 \pm 60.9 \mathrm{~N} \cdot \mathrm{m}(3.71 \pm 0.73$ $\left.\mathrm{N} \cdot \mathrm{m} \cdot \mathrm{kg}^{-1}\right)$, respectively. The existing literature does not provide values of static torque of both upper and lower extremities measured in the same handball players.

A high level of muscle strength gives the whole team an advantage in some handball game actions such as hitting, blocking, pushing, and holding (Gorostiaga et al., 2006). Strength training should be conducted in such a way that all muscle groups are developed proportionally with special attention to maintaining balance in strength of antagonistic muscle groups.

Gorostiaga et al. (2006) noted that changes of strength in elite athletes during a 45-week season were relatively small and ranged from 1 to $4 \%$. In our study values of the maximum joint torque increased significantly by 10 to $24 \%$ over a two-year training cycle. However, the changes of their relative values did not reach the level of statistical significance.

Significant differences were found only for the sum of joint torque of lower extremities (SLER), trunk (ST) and the total sum of joint torques (TOTAL). It may indicate that the increase of strength was caused by greater mass of the muscle tissue, which is in line with the Matthys' et al. (2013) study.

The maximum relative power achieved by the handball players in our study in the RSA test was higher than that achieved by players from the leading teams tested by Gharbi et al. (2015) and Popadic (2009). Our results are in agreement with those reported by Norkowski (2002) for the best Polish handball players from junior and cadet categories. On the other hand, Tunisian athletes representing the national level at the age of 17.2 years (Hermasi, 2015) and players from the Greek handball league (Nikolaidis and Ingebrigtsen,
2013) achieved greater power values than athletes tested in our study. However, it should be noted that there were differences in the methodology applied in those studies. Unlike our research, the athletes performed only a single effort to develop maximum power, which could have had an impact on the results achieved.

In our study, significant changes in maximum power and work (both relative and absolute) were observed within the two-year training cycle. This was in line with the results of Matthys et al. (2013), who reported both a decrease in sprint time and a decrease in beep-test time. In a cross-sectional study conducted by Norkowski (2002), there were also significant differences in peak power measured in athletes aged 17 years versus those aged 18 years. Yet, it should be noted that the direction and volume of mechanical work changes are similar to changes observed for power in the RSA test. An increase of mechanical work is accompanied by an increase of the fatigue index, which is expressed as a percent decrease of work between successive repetitions.

\section{Conclusion}

The main finding of the study is that the peak power and absolute work in the RSA test, maximal power and height of a jump in the ACMJ, CMJ and SPJ as well as joint torque increased with training experience and age in the group of youth handball players. However, the changes of relative torque values (related to body mass) were not significant.

Since the results of the comparative studies are different, there is a need to establish reference values for a long-term follow-up of physical abilities of handball players. Such data could make it easier for coaches to select players for teams in different age categories.

\section{Acknowledgements}

This work was supported by the Fund for the Development of Physical Culture from the Ministry of Sport and Tourism, Republic of Poland.

\section{References}

Bencke J, Damsgaard R, Saekmose A, Jørgensen P, Jørgensen K, Klausen K. Anaerobic power and muscle strength characteristics of 11 years old elite and non-elite boys and girls from gymnastics, team handball, tennis and swimming. Scand J Med Sci Sport, 2002; 12(3): 171-178 
Bishop D, Spencer M, Duffield R, Lawrence S. The validity of a repeated sprint ability test. J Sci Med in Sport / Sports Med Australia, 2001; 4(1): 19-29 Retrieved from http://www.ncbi.nlm.nih.gov/pubmed/11339490

Bishop D, Edge J, Goodman C. Muscle buffer capacity and aerobic fitness are associated with repeatedsprint ability in women. Eur J Appl Physiol, 2004; 92(4-5): 540-547 https://doi.org/10.1007/s00421-0041150-1

Boguszewska K, Boguszewski D, Buśko K. Specjal Judo Fitness Test and biomechanics measurements as a way to control of physical fitness in young judoists. Archives of Budo, 2010; 6(4): OA205-209

Chelly MS, Hermassi S, Shephard RJ. Relationships between power and strength of the upper and lower limb muscles and throwing velocity in male handball players. J Strength Cond Res, 2010; 24(6): 14801487

Chittibabu B. Estimation of relationship between maximal oxygen consumption and repeated sprint ability of male handball players. In. J. Phys Educ Fit Sport, 2014; 3(2): 79-84

Edge J, Bishop D, Goodman C, Dawson B. Effects of high- and moderate-intensity training on metabolism and repeated sprints. Med Sci Sports Exerc, 2005; 37(11): 1975-82 Retrieved from http://www.ncbi.nlm.nih.gov/pubmed/16286869

Gajewski J, Michalski R, Buśko K, Mazur-Różycka J, Staniak Z. Countermovement depth - a variable which clarifies the relationship between the maximum power output and height of a vertical jump. Acta Bioeng Biomech, 2018; 20(1): 127-134

Gharbi Z, Dardouri W, Haj-Sassi R, Chamari K, Souissi N. Aerobic and anaerobic determinants of repeated sprint ability in team sports athletes. Biol. Sport, 2015; 32(3): 207-212

Girard O, Mendez-Villanueva A, Bishop D. Repeated-sprint ability-Part I. Sport Med 2011; 41(8): 673-694

Gorostiaga EM, Granados C, Ibanez J, Gonzalez-Badillo JJ, Izquierdo M. Effects of an Entire Season on Physical Fitness Changes in Elite Male Handball Players. Med Sci Sports Exerc, 2006; 38(2): 357-366

Gorostiaga EM, Granados C, Ibanez J, Izquierdo M. Differences in physical fitness and throwing velocity among elite and amateur male handball players. Int J Sports Med, 2005; 26(03): 225-232

Gorostiaga EM, Izquierdo M, Iturralde P, Ruesta M, Ibáñez J. Effects of heavy resistance training on maximal and explosive force production, endurance and serum hormones in adolescent handball players. Eur J Appl Physiol, 1999; 80: 485-493

Granados C, Izquierdo M, Ibàñez J, Bonnabau H, Gorostiaga EM. Differences in physical fitness and throwing velocity among elite and amateur female handball players. Int J Sports Med, 2007; 28(10): $860-867$

Granados C, Izquierdo M, Ibàñez J, Ruesta M, Gorostiaga EM. Effects of an Entire Season on Physical Fitness in Elite Female Handball Players. Med Sci Sports Exerc, 2008; 40(2): 351-361

Hermassi S, Aouadi R, Khalifa R, van den Tillaar R, Shephard RJ, Chelly MS. Relationships between the YoYo intermittent recovery test and anaerobic performance tests in adolescent handball players. J Hum Kinet, 2015; 45(1): 197-205

Hermassi S, Chelly MS, Fathloun M, Shephard RJ. The effect of heavy- vs. moderate-load training on the development of strength, power, and throwing ball velocity in male handball players. J Strength Cond Res, 2010; 24(9): 2408-2418

Marques MAC, Gonzalez-Badillo JJ. In-season resistance training and detraining in professional team handball players. J Strength Cond Res, 2006; 20(3): 563-571

Marques MC, Van Den Tillaar R, Vescovi JD, González-Badillo JJ. Relationship between throwing velocity, muscle power, and bar velocity during bench press in elite handball players. Int J Sport Physiol, 2007; 2(4): 414-422

Matthys SPJ, Vaeyens R, Fransen J, Deprez D, Pion J, Vandendriessche J, Vandorpe B, Lenoir M, Philippaerts R. A longitudinal study of multidimensional performance characteristics related to physical capacities in youth handball. J Sports Sci, 2013; 31(3): 325-334

Nikolaidis PT, Ingebrigtsen J. Physical and physiological characteristics of elite male handball players from teams with a different ranking. J Hum Kinet, 2013; 38: 115-124

Norkowski H. Anaerobic power of handball players representing various sport levels. J Hum Kinet, 2002; 7 : $43-50$ 
Orysiak J, Busko K, Mazur-Różycka J, Michalski R, Gajewski J, Malczewska-Lenczowska J, et al. Relationship Between ACTN3 R577X Polymorphism and Physical Abilities in Polish Athletes. J Strength Cond Res, 2015; 29(8): 2333-2339

Szulc A, Buśko K, Sandurska E, Kołodziejczyk M. The biomechanical characteristics of elite deaf and hearing female soccer players: comparative analysis. Acta Bioeng Biomech, 2017; 19(4): 127-133

Thorlund JB, Michalsik LB, Madsen K, Aagaard P. Acute fatigue-induced changes in muscle mechanical properties and neuromuscular activity in elite handball players following a handball match. Scand $J$ Med Sci Sports, 2008; 18: 462-472

van den Tillaar R, Ettema G. Effect of body size and gender in overarm throwing performance. Eur J Appl Physiol, 2004; 91(4): 413-418

Vicente-Rodriguez G, Dorado C, Perez-Gomez J, Gonzalez-Henriquez JJ, Calbet JAL. Enhanced bone mass and physical fitness in young female handball players. Bone, 2004; 35(5): 1208-1215

Williams AM, Reilly T. Talent identification and development in soccer. J Sports Sci, 2000; 18: 657-667

Ziv G, Lidor R. Physical characteristics, physiological attributes, and on-court performances of handball players: A review. Eur J Sport Sci, 2009; 9: 375-386

\section{Corresponding author:}

\section{Krzysztof Buśko}

Department of Anatomy and Biomechanics

Kazimierz Wielki University

Sportowa 2

85-091 Bydgoszcz

Poland

Phone: 523231706

E-Mail: krzysztof.busko@ukw.edu.pl 